\title{
Management of Individual and Organizational Design Knowledge
}

\author{
Tz-Ying Lin ${ }^{1}$ and Ding-Bang Luh ${ }^{2}$ \\ ${ }^{1}$ Innovation Service Sec., ASUS Tek Computer INC., \\ Taipei City, Taiwan, ROC \\ im.grace.001@gmail.com \\ ${ }^{2}$ Department of Industrial Design, National Cheng Kung University, \\ Tainan City, Taiwan, ROC \\ dingbangluh@gmail.com
}

\begin{abstract}
Before starting to formulate design concepts, designers usually gather relevant information to explore design problems and facilitate concept development. The information search behavior is a comprehensive consideration, which differs from the specific search of design methods. The research analyzes the factors that influence design information search behavior and constructs a general information search behavior structure. Through in-depth interviews with designers with various levels of experience and with the code analysis method in Grounded Theory and the Interpretive Structural Modeling approach, a behavior model of design information search is established. The research results can provide design information managers with the reference for information search planning and allow staff who develop design information database to better understand the factors and aspects involved in design information search behavior. This study the knowledge management in design companies' model are designed based on the designer's search behavior structure, and chooses NOVA Design as the case of the research. Deeply investigating the knowledge required during the design process, methods used by the designer to obtain the relevant information, including design knowledge and storage methods made by designer during the designing process.
\end{abstract}

Keywords: Design Management, Knowledge Management, Design Information, Search Behavior, Grounded Theory.

\section{Design Work Involves Knowledge Management}

Designing industries are composed of knowledge workers, who are most important assets of knowledge organizations. To seek sustainable development, the issue for the designing industries to face is how to internalize and deepen the knowledge into the organizations and rapidly discover new knowledge [1]. Now that the structures of industry modes are changing, designing companies have to pass on the professional knowledge and experience to new employees, and shorten their learning curve and lower training cost [2]. The power of knowledge and Knowledge Management are 
now the powerful tools for the companies to compete with others. In Taiwan, most of the designing companies are of small or medium scales. Their employees are mobile, the knowledge has been accumulated only slowly, and key know-how is concentrated on the few professional workers. The absence of the mechanism of effective management of designing knowledge will limit the raise of productive ability. Therefore Knowledge Management is of importance and necessity for designing companies. In the literature, however, we see few studies have focused on designers' personal behavior, exploring how designers develop their search behavior at the initial stage, how the internal process of designing, including the designing knowledge produced during the process, is effectively stored and shared with others members through proper mechanism and how demands from clients and designing companies are sufficiently satisfied. Those are what this study aims at.

\section{Information Search as a Crucial Work before Concept Development}

In design activities, "information search" is a general but important behavior. The design information management research report conducted by British Design Information Group [3] points out that, when designers design, they spend up to $60 \%$ of the time looking for design information. The formation of core concepts in design activity requires information, experience and the ability to convert [4]. As Roozenburg and Eekels [5] suggest in a research on design procedure, designers form concepts based on the information they obtain, make product proposals, start the procedure and go on to turn the proposed ideas into substantial products. The information search before concept development is extensive and comprehensive. In the process of searching information, there are individual differences because designers have their own interests and considerations. With the accumulation of experience, designers will establish their own search methods or behaviors. Such individual differences affect design ability. Kuan [6] believes that in the stage of concept formation, designers usually design under the interaction and manipulation of subjective experience and objective conditions. The ability to search design information has major influence on the quality of the concept generated at this stage. When designers are inexperienced at searching information, the design ideas will be limited. If designers acquire better search ability and higher flexibility, they can come up with solutions beyond their original knowledge base and start the process of innovative development.

This study emphasizes on exploration of designers' search behavior seeking information and designing knowledge and their ways of knowledge management when they have finished their productions. There is no intention in this study to explore the processes and methods of creating knowledge, mainly because knowledge creation is a process necessary to the whole design activity, but current research is less directed at the front end and back end, and mainly because these processes and methods vary a lot, depending on companies' orienting types and the businesses they serve, and are difficult to be discussed in a unified frame of theory. Therefore, this study analyzes designers' search behavior before developing their concepts. We go further and try to 
construct companies' knowledge management frame, taking the company NOVA Design as a verification object. Through in-depth exploration, a knowledge management frame is sorted out and offered here, which it is expected will be a reference for companies to do knowledge management.

\section{Design Information Search Behavior}

Qualitative approach is adopted in this research. The selected interview subjects of this research were considered by the influential factors of the general information search behavior. The interview cases were selected by design experience and organization features, which have most diversity with objectivity in the personal and environmental perspectives. In terms of design experience, subject designers were chosen by years of design experience they had, and by numbers of products they designed. In terms of organization feature, designers were selected by the configuration of the organizations they belong and the type of products they design. This research selected eight interview subjects from four design organizations, which were "professional design consultancies" and "in-house design departments" that design IT products and home appliances. One senior designer and one junior designer were selected from each of the four design organizations as interviewees. For analyzing the information obtained from interviews, one of the most scientific methods among all qualitative research methods, Grounded Theory approach proposed by authoritative sociology scholars Strauss and Corbin [7], is employed. This research uses its coding procedure to analyze the preliminary data obtained through interview. The relationships between factors are then determined with Interpretive Structural Modeling (ISM) method. The steps of this research analysis are as follows (Fig. 1).

In the following, the Design Information Search Behavior structure is established step by step according to data analysis steps.

1. Coding concepts: Analyze the transcript obtained through interviews, and select the key sentence regarding information search behavior for concept development. And then analyze the content of the sentence; when it is necessary, return to the transcript and examine the context so as to determine the main idea discussed in this key sentence. Number and name the concept conveyed by this sentence.

2. Collecting and classifying concepts: Some concepts point to a larger concept that can encompass all of them, and this larger concept is called "scope." Likewise, each scope is given a name after classification. The scopes obtained in this step are the perspectives in design information search behavior.

3. Integrating with factors within the perspective: Perspectives are obtained after concepts are collected and classified. Factor content within this perspective, the relationship between each factor within this perspective, and the relationship between factors within this perspective and factors within other perspectives can be seen from concept names. 


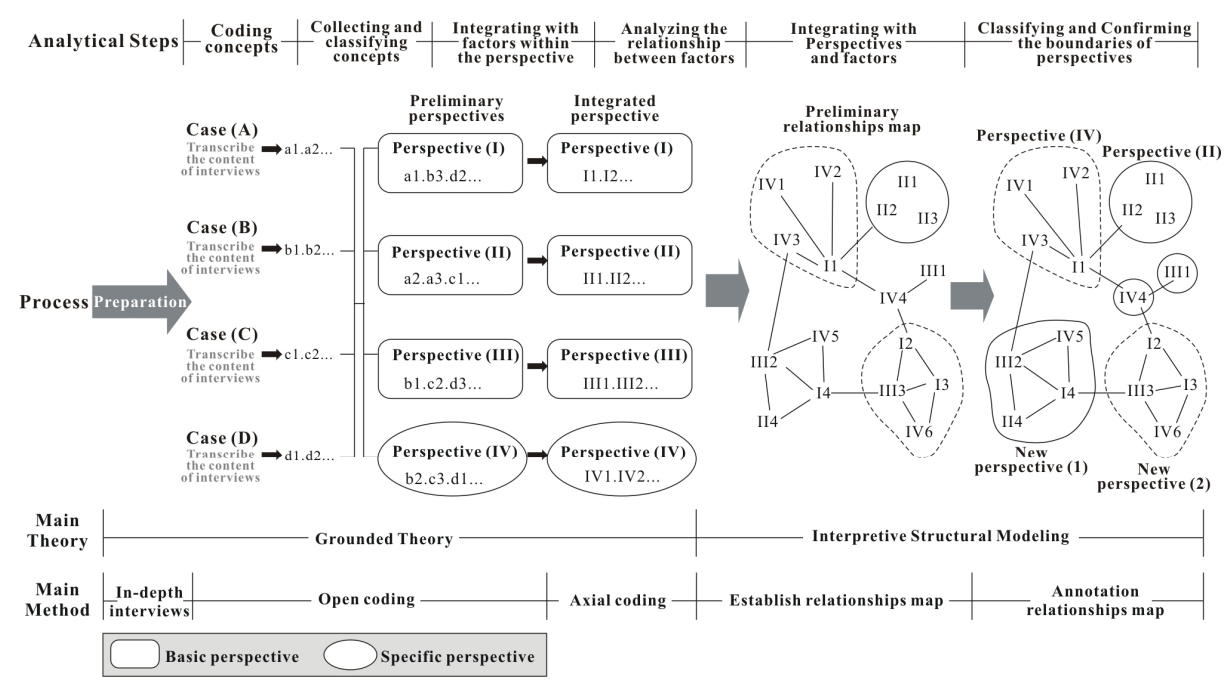

Fig. 1. Research framework and method

4. Analyzing the relationship between factors: Employ the matrix in this step and follow the prescribed order, the relationship structure between factors can be obtained. The goal of this step is to build the factor relationship structure of design information search behavior for concept development, so only the factors related to factors in other perspectives are placed in the matrix.

5. Integrating with Perspectives and factors: First of all, determine whether certain relationships exist between each factor and build the relationship matrix; furthermore, build the shifted matrix according to the principle "if a influences $b$ and be influences c, then a influences c." And then, calculate the sum of relationships in the rows and columns of the shifted matrix. Add all horizontal numbers to get the sum $\mathrm{D}$, and add all vertical numbers to get $\mathrm{R}$. Calculate the sum of and difference between each factor's D and R; employ the sum of D and R as the $\mathrm{x}$ axis of the coordinate and the difference between $\mathrm{D}$ and $\mathrm{R}$ as the $\mathrm{y}$ axis. Finally, locate each factor on the coordinate plane and connect each factor with arrows according to the relationship matrix in order to complete the relationships map.

6. Classifying and confirming the boundaries of perspectives: After obtaining the preliminary relationships map, the factors that originally belong to the same perspective may still group together, but they may also disperse and group together with factors within other perspectives. At this point it is necessary to return to the original data and examine whether the grouping factors can form a new perspective. The relationships within and between perspectives should also be explored.

Adjustments made based on the following steps, results in the information search behavior framework shown in Fig. 2. 


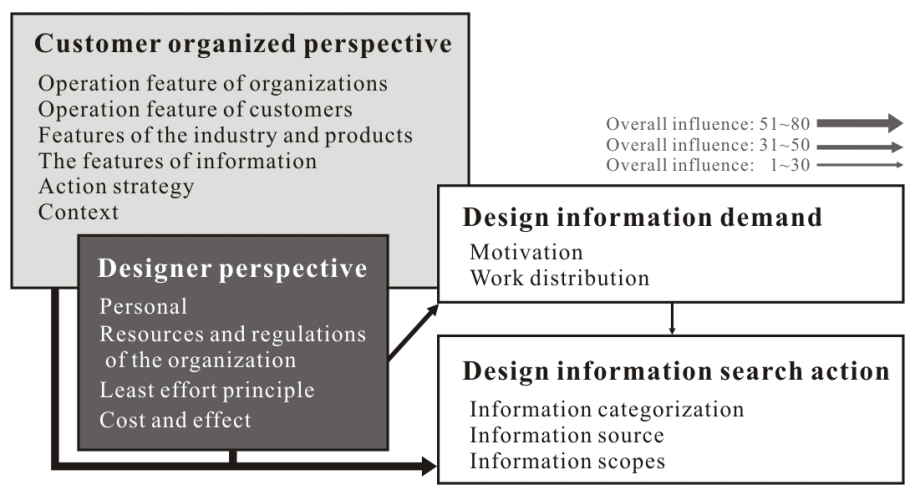

Fig. 2. Design information search behavior framework

Designers mainly are influenced by "Customer organized perspective" or "Designer perspective" when performing design information search behavior, and caused various "design information demands" and, in turn, change "Design information search action".

"Customer organized perspective" is the main influenced perspective, it is closely related to "Designer perspective" and may directly influences "Design information demand", it can also strongly directly influence the overall "Design information search action", and able to know the organization and state of the customer towards designer's information search behavior possesses an decisive function, designers may have different information demand because of different industry or product, and in turn, change information search action. Its content of six categories includes "Operation feature of organizations", "Operation feature of customers", "Features of the industry and products", "The features of information", "Action strategy", and "Context".

"Designer perspective" is the secondary influential perspective, including "Personal", "Resources and regulations of the organization", "Least effort principle", and "Cost and effect", designers will consider different options between "Least effort principle", "Cost and effect", and "Motivation" based on personal background and demand and adopt different "Design information search action", sometimes designers may be influenced by "Customer organized perspective" and have different "Design information demand" or take different "design information search action".

"Work distribution" is of the most influential within "Design information demand", designers perform the design information search due to work distribution demand, stimulate different ideas, understand subject and direct application, besides, design organization carries the decisive function when designers perform design information search behavior, basically designers belongs to the same organizations have similar design information search behavior, if there is a difference, it is influenced by "Designer perspective".

"Design information search action" is a combined influence of "Customer organized perspective", "Designer perspective", and "Design information demand". A designer is influenced by many sources; the "design information search action" taken after consideration mainly has three: categorize information demand, select source of information, and select information category. 


\section{Design Knowledge Management of Design Companies}

Design knowledge management is by and large "the transformation process of personal or organizational knowledge into what can be applied by every member and the maximization of corporate value". This study the knowledge management in design companies' model are designed based on the designer's search behavior structure.

A structure of the knowledge storage and sharing mechanisms of design companydesigner relations is proposed in this research (Fig. 3). The structures is an integration of the Structure of Knowledge Storage proposed by Chang [8] and Hsu [9] and the concept of "Knowledge Spiral" suggested by Nonaka [10] and Lin [11] . The structure serves as the core model of this research. Design knowledge mainly stores in individuals and organizations in the form of explicit and tacit knowledge. Fig. 3 can be transcribed into Fig. 4 for the sake of convenience for discussion.

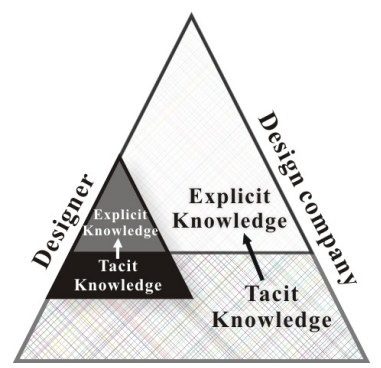

Fig. 3. Organization-Designer relations

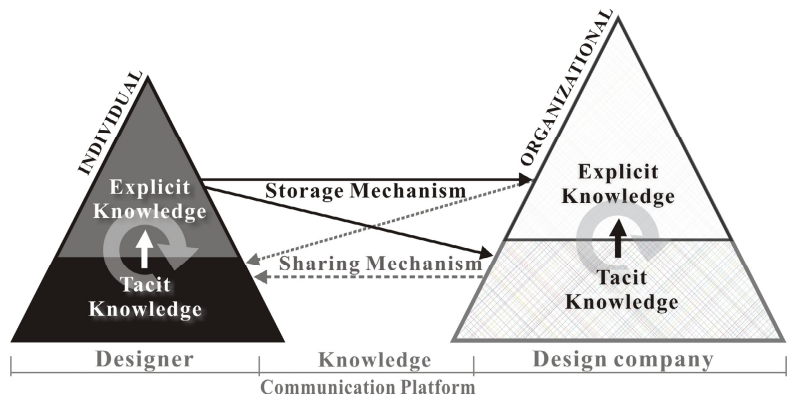

Fig. 4. Knowledge Storage and Sharing Structure of Design Companies

The questionnaires are designed based on the designer's search behavior structure. Survey forms were designed based on qualitative content from the documents and early findings from case interview. The Questionnaire Design employs with partially open-ended questions. There were 4 different kinds of surveys: the designer, within the design department, design and other departments, and design companies and other enterprises (such as co-operative, customer and competitive enterprises). This study chooses NOVA Design as the case of the research. There were a total of 28 people who were interviewed (19 designers, 4 team leaders, 2 chief design inspectors and 3 entrepreneurs). Deeply investigating the knowledge required during the design process, methods used by the designer to obtain the relevant information, including design knowledge and storage methods made by designer during the designing process. This research turns case interview content into transcripts. Questionnaires are analyzed through content analysis and basic statistics. Systematic induction is employed to build the design company's design knowledge sharing, storage mode and management mechanism. The design company's design knowledge management mode figure (Fig. 5) is also established. 


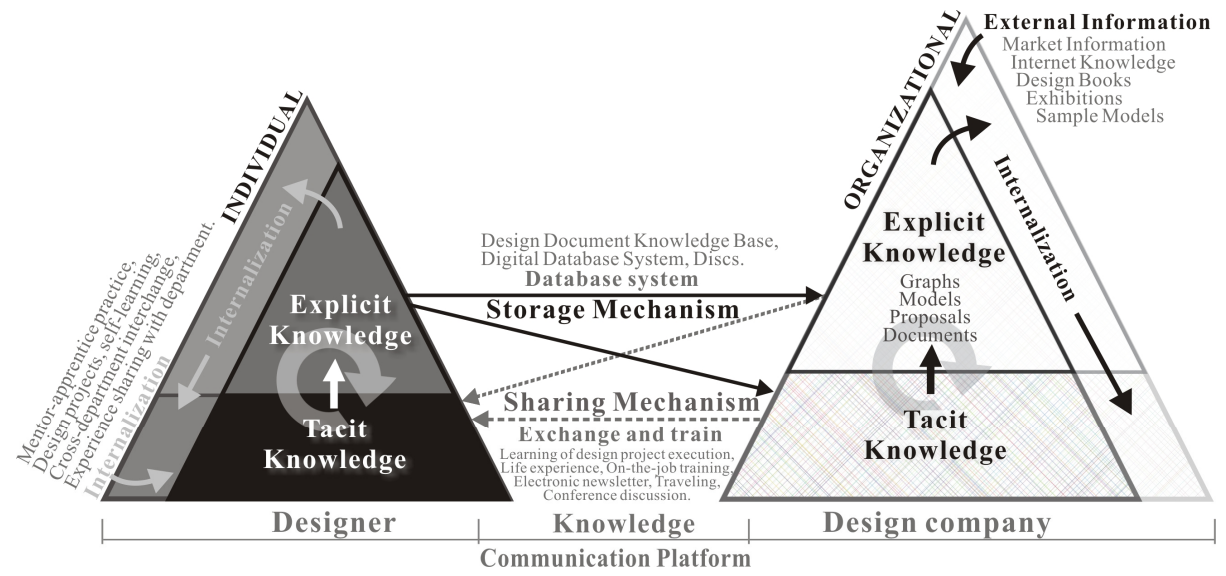

Fig. 5. Design Knowledge Management Model of Design Companies

As indicated in Fig.5, the explicit knowledge of organizations includes design graphs, proposals, documents and models. Organizations also collect external information on a regular basis (such as market information, internet knowledge, design books, exhibitions, sample models etc.) for the designers' reference. The tacit knowledge of organizations can be conveyed to designers through interchange and training mechanisms such as electronic newsletter, conference discussion, life experience, learning of design project execution, on-the-job training, traveling. Designers can accumulate individual tacit knowledge through execution of design projects, experience sharing with department, cross-department interchange, self-learning and mentor-apprentice practice, etc. Through the process of design project execution, tacit knowledge is displayed in externalized manners such as speech, drawings or projects. The ideas and results of design will be stored in the database. As a result, some of the design styles and features of individual designers will be accumulated as the tacit knowledge of organizations.

The Design knowledge is produced and used by the iteration of "tacit- explicit". Following the cycle, designers will accumulate tacit knowledge and create more explicit knowledge. Meanwhile, the explicit and tacit knowledge of design companies is also growing (Fig.6). With the increase of explicit knowledge and the expansion of tacit knowledge, the knowledge entity of design companies and designers will grow accordingly through continuous absorption and accumulation.

This study further looks into the aspect or type of designer grown up in design knowledge, including three items (Fig. 7): (A) "Grow with": the designers, grown up with organizations, have great ability of leadership and management. (B) "Within": the designers only enhance the design knowledge and skill, have high design efficiency. (C) "Without": the designers, with extra vision except design skill, have development ability with breakthrough thinking. 


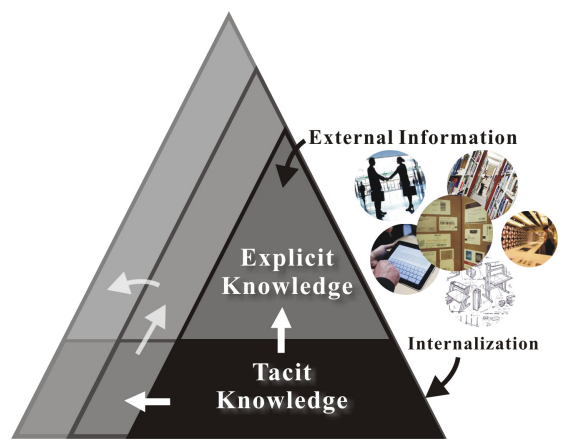

Fig. 6. Design knowledge increasing

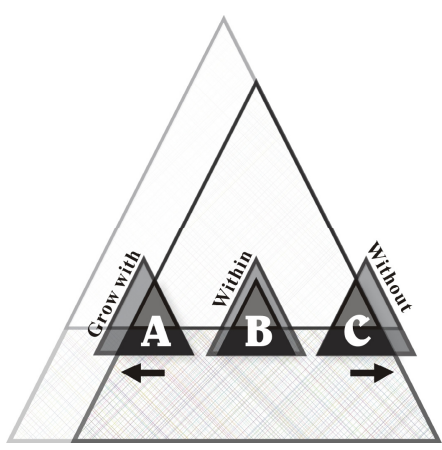

Fig. 7. Grow up in the direction differently

\section{Design Information Search Behavior of Three Types Designer}

It is found in this study that there are cross influence between with three type designer and design information search behavior. Various types of designer that demand content of information are different, so they have different design information search action. This study further to explore three type designer's search behavior and the following are the results:

"Grow with" type of designers is sensitive; they can observe the direction of organizations develop. The "Grow with" type's designer was grown up with organizations direction, that they own great ability of leadership and management. When searching information, they pay attention and collect customer organized information and do judgments on, for instance, relation of customer with companies, or possible development in the future. This type of designers tends to need diverse and wide information, and after designer's personal careful consideration and judgment, they were proceeding as the design information search action. After the data analysis found, "Grow with" type of designers search behavior model same of thesis frameworks, with a slight difference only in figures of "Total influence".

"Within" type of designers pay attention to new technology and science, material, and skills. They are very emphasizing of efficiency. They refine continuously their skills, so their designing ability is of high efficiency. This type of designers doesn't enjoy meetings. They are not interested in communication with customer. So, could find in "Within" type of designers search behavior model, the total influence of "Customer organized perspective" is only 10 . The main influences to them are "Work distribution" (Total influence is 50). "Within" type of designers will proceed evaluation at "Personal" and "Least effort principle", then driven their search behavior.

"Without" type of designers have development ability with breakthrough thinking, because they enjoy new challenges. They are happy and interested when companies have cases to do for customer from different fields. They will be eager to try. This type of designers emphasize on having knowledge and ability outside of their own fields. They like "study" customer, and try to deeply understand the customer's background, products and skills. So, could find in "Without" type of designers search 
behavior model, the "Customer organized perspective" is very influential, the total influence is over 80. In the "Customer organized perspective", the factors that have greater influences in Customer are: "Features of the industry and products", "The features of information", and "Context". The "Customer organized perspective" will directly influence designer, which directly urges them to proceed with "Design information search action"

\section{Conclusions and Suggestions}

In an era of knowledge being the main instrument of competition, knowledge management of design companies will become the crucial power in creating a new wave of Taiwan's economic miracle. For knowledge managers of design companies, the tacit knowledge of designers is the real knowledge competitiveness of design companies. Therefore, knowledge management of design companies discussed in the study is not accomplished merely through the use of information technology, but by observing the designers' behavior, along with case analysis, investigation, adjustment, verification and modification, to build a better model eventually.

In terms of research methods, the study employs the coding procedures of Grounded Theory to analyze the interview data and obtain concepts, factors and perspectives. But the coding procedures do not have a concrete, detailed operation method for clarifying the complex relationships between factors or perspectives and for establishing a structure, so the study also employs ISM with a detailed operation method to link the relationships between factors or perspectives, analyzing the data effectively, and build a more definite structure out of the complexity of these relationships, which is a breakthrough in qualitative research methods.

The research results show that the proportion of designer types can influence the design capacity of a design company, also changing the form of the whole design organization, which has a decisive impact on the designers' search behavior of design information. Therefore, the designer classification mode provided by the study is significant and instrumental to the sustainable development and constitution examination of design organizations. Besides, the designers' search behavior of design knowledge can provide reference for design information managers in the planning of information search, helping design information database developers understand the factors and aspects involved in the information search behavior of designers. So it goes without saying that the "knowledge management of design companies" proposed in the study is of great importance and value.

Acknowledgements. Part of the paper's research results derive from National Science Council's research project: "The Study in Design Knowledge Management of Design Consultancies I (NSC 95-2221-E-006 -100)" and "The Study in Design Knowledge Management of Design Consultancies II (NSC96-2221-E-006-091)". Owing to the funding from National Science Council, the study is completed successfully. Also, special thanks go to my senior Ching-Yi Chen for her provision of preliminary research results, and my classmate Shun-Hung Chen for his participation in the research. I am much obliged. 


\section{References}

1. Chen, W.L., Jeng, S.S., Chu, P.Y., Su, P.C.: Intention focus of the next society- organize the view of knowledge sharing, pp. 135-158. Taiwan Design Center (2004)

2. Hsu, M.T.: Creation and creative destruction: The economics master of Schumpeter. Scientific Development 403, 70-75 (2006)

3. Crossland, R., Sims Williams, J.H., McMahon, C.A.: An Object-Oriented Design Model, Incorporating Uncertainty for Early Risk Assessment. In: Proc. Int. Conf. Eng. Design (ICED 1995), pp. 1555-1556. Czech Republic, Praha (1996)

4. Thomas, H.D.: Thinking for a Living: How to Get Better Performance and Results from Knowledge Workers. Client Distribution Services (2006)

5. Roozenburg, N.F.M., Eekels, J.: Product design- Design basis and methodology, p. 13, 100, 111. Six shutting Publishing house, Taipei (1995)

6. Kuan, C.N.: Thing foot-path of the products- Design the formulation of the intention, development and application, Taipei, Artist, pp. 123, 127-128, 195 (2001)

7. Strauss, A., Corbin, J.: Study outline in quality, Flow out one edition of societies hugely, Taipei, pp. 64, 69-84, 109-131, 133-162 (1997)

8. Chang, W.C.: Research on Management of Knowledge in newspaper office, Department of Journalism. National Chengchi University, Taiwan (2001)

9. Hsu, C.Y.: Knowledge management of medium organization: Regard media news department of Taiwan as the real example target, Taiwan managing and learning, EMBA (2002)

10. Nonaka, I.: The Knowledge -Creating Company. Harvard Business Review, 96-104 (November-December 1999)

11. Lin, L.H.: Research on Design knowledge transfer. National Yunlin University of Science and Technology, Taiwan (2002) 